\title{
Determination of personal care products and hormones in leachate and groundwater from Polish MSW landfills by ultrasound-assisted emulsification microextraction and GC-MS
}

\author{
Justyna Kapelewska $^{1} \cdot$ Urszula Kotowska $^{1} \cdot$ Katarzyna Wiśniewska $^{1}$
}

Received: 19 June 2015 / Accepted: 2 September 2015 / Published online: 18 September 2015

(C) The Author(s) 2015. This article is published with open access at Springerlink.com

\begin{abstract}
Determination of the endocrine disrupting compounds (EDCs) in leachate and groundwater samples from the landfill sites is very important because of the proven harmful effects of these compounds on human and animal organisms. A method combining ultrasound-assisted emulsification microextraction (USAEME) and gas chromatography-mass spectrometry (GC-MS) was developed for simultaneous determination of seven personal care products (PCPs): methylparaben (MP), ethylparaben (EP), propylparaben (PP), buthylparaben (BP), benzophenone (BPh), 3-(4methylbenzylidene)camphor (4-MBC), $N, N$-diethyltoluamide (DEET), and two hormones: estrone (E1) and $\beta$-estradiol (E2) in landfill leachate and groundwater samples. The limit of detection (LOD)/limit of quantification (LOQ) values in landfill leachate and groundwater samples were in the range of $0.003-0.083 / 0.009-0.277 \mu \mathrm{g} \mathrm{L}^{-1}$ and $0.001-0.015 / 0.002-$ $0.049 \mu \mathrm{g} \mathrm{L}^{-1}$, respectively. Quantitative recoveries and satisfactory precision were obtained. All studied compounds were found in the landfill leachates from Polish municipal solid waste (MSW) landfills; the concentrations were between 0.66 and $202.42 \mu \mathrm{g} \mathrm{L}^{-1}$. The concentration of pollutants in groundwater samples was generally below $0.1 \mathrm{\mu g} \mathrm{L}^{-1}$.
\end{abstract}

Keywords Endocrine disrupting compounds · Hormones · Personal care products · Groundwater · Landfill leachate . Ultrasound-assisted emulsification microextraction · Gas chromatography-mass spectrometry

Responsible editor: Roland Kallenborn

Urszula Kotowska

ukrajew@uwb.edu.pl

1 Institute of Chemistry, University of Bialystok, ul. Ciołkowskiego 1K, 15-245 Bialystok, Poland

\section{Introduction}

Along with the civilization development and the evolution of human lifestyle, there was an increase in consumption and thus the formation of more and more wastes of diversified composition. Despite the emerging research on the risks associated with the solid waste landfills, there are still plenty of unresolved issues concerning the negative effects of their operation. This is mainly due to changes in the solid waste (Renou et al. 2008). The landfill leachate is a heterogeneous matrix, formed by excess water percolating through the waste layers in the landfills, and is commonly referred to as "difficult wastewater" (Foo et al. 2013). The ecotoxicological studies of landfill leachates demonstrate their acute toxicity (Alkassasbe et al. 2009; Kalka 2012). In municipal solid waste landfills, various kinds of material are disposed of. They include waste products containing endocrine disrupting compounds (EDCs) and incineration residue that includes dioxin (Asakura et al. 2004). In the case of an insufficient insulation system between the mass of landfilled waste and the soil environment, organic pollutants can easily seep into ground and surface water, and to drinking water (Nomngongo et al. 2012; Rosi-Marshall and Royer 2012). This is one of the most important issues associated with the impact of the landfill on the aquatic environment. This threat is all the more real, because many landfill sites in Poland use the so-called natural insulating barrier, which does not adequately protect the aquatic environment from organic pollutants.

Standard environmental monitoring measures applied toward landfill leachate or seepage mainly include the determination of bulk parameters, such as total organic carbon, dissolved organic carbon, chemical oxygen demand, biological oxygen demand as well as element analysis of anions, cations, and heavy metals (Preiss et al. 2012). The problems of the occurrence of EDCs in the landfill leachate from municipal 
solid waste (MSW) landfill were undertaken by scientists only several times so far. This may be connected to the fact that the detection of trace compounds in landfill leachate is a difficult task, due to the very complex matrix of leachate, more complicated than majority of liquid environmental samples. Landfill leachate contains large amounts of inorganic salts, heavy metals, nitrogen compounds, and different kinds of organic compounds, including humic substances, which cause their dark color. In previous publications, designations of phthalates, octylphenol, nonylphenol, bisphenol A, and polybrominated diphenyl ethers (PBDEs) in landfill leachate have been described (Yamamoto et al. 2001; Asakura et al. 2004; Dos Santos et al. 2004; Kurata et al. 2008; Odusanya et al. 2009; Kwan et al. 2012; Zhang et al. 2012; Kalmykova et al. 2013). Concentrations of target EDCs in the landfill leachate fit within a very wide range from a few nanograms per liter up to tens of milligrams per liter.

Methylparaben (MP), ethylparaben (EP), propylparaben (PP), and buthylparaben (BP) are used as preservatives in pharmaceutical, personal care, and food products. In the European Union (EU), the use of parabens in cosmetics is limited to a maximum concentration of $0.4 \%(w / w)$ for one type of parabens and of $0.8 \%(w / w)$, expressed as p-hydroxybenzoic acid, for parabens mixtures (European Commission 1976). Regarding their toxicological effects, these compounds have shown estrogenic activity and are potentially toxic for certain aquatic organism; however, it is relatively weak in comparison to toxicity of E2 (Harvey and Everett 2004). Benzophenone (BPh) and 3-(4-methylbenzylidene)camphor (4-MBC) are sunscreen agents. They have the ability to absorb and dissipate ultraviolet light. Therefore, it is used in many cosmetics and sunscreens to protect human skin from ultraviolet radiation (Pietrogrande and Basaglia 2007). Diethyltoluamide (DEET) is one of the most widespread and efficient insect repellents (e.g., mosquito). DEET is known to be persistent (Costanzo et al. 2007) but weakly toxic toward fishes, birds, and invertebrates (Pietrogrande and Basaglia 2007). E1 and E2 are examples of natural estrogen found in birth control pills. Prenatal exposure to both natural and synthetic estrogens has been associated with increased occurrence of vaginal and breast tumors in humans and uterine tumors in animals. Exposure to natural steroid hormones will likely elicit an effect because these hormones can readily bind to receptors to activate transcription and protein synthesis (Streets 2008).

MP, EP, PP, BP, and BPh were found in different environmental samples: tap water, surface water, and influent and effluent wastewater (Trenholm et al. 2008; Regueiro et al. 2009b; Casas Ferreira et al. 2010; Gracia-Lor et al. 2012; Kotowska et al. 2013; Zhang and Lee 2013). DEET was found in river water, sea water, and wastewater samples (Trenholm et al. 2008; Calza et al. 2011; Kotowska et al. 2013; Loos et al. 2013). E1 and E2 were detected in river water and influent and effluent wastewater samples (Kumar et al. 2009; Kotowska et al. 2013). 4-MBC was found in tap water and influent and effluent wastewater so far (Liu et al. 2011, 2012; Kotowska et al. 2013). There is no information on the presence of hormones and personal care products (PCPs) in the landfill leachate from MSW landfill. Furthermore, there is no information about the determination of EDCs in groundwater samples collected from piezometers located under the landfill sites.

Determination of the hormones and PCPs in environmental samples is a very difficult task due to their low concentrations and complex matrix of the substances. In most of cases, these contaminants are present at levels of several nanograms per liter to several micrograms per liter (Trenholm et al. 2008; Calza et al. 2011; Gracia-Lor et al. 2012; Liu et al. 2012). Only in the last decades has been developed the analytical methods for the determination of compounds present in the environment in ultratrace quantities. The most extensively used technique for the isolation of the EDCs from the environmental samples is the solid-phase extraction (SPE) (Trenholm et al. 2008; Calza et al. 2011; Gracia-Lor et al. 2012; Liu et al. 2012; Loos et al. 2013). However, application of SPE is time-consuming and labor-intensive and needs a quite large amount of organic solvents, specially comparing with microextraction techniques. This is why more and more frequently, there is a need for methods enabling to eliminate or substantially reduce the consumption of organic solvents during the analytical procedure. To isolate $\mathrm{BPh}$ and 4-MBC, apart from SPE, also dispersive liquid-phase microextraction (DLPME) and vortex-assisted liquid-liquid microextraction (VALLME) are applied (Zhang and Lee 2012, 2013). In the case of parabens, also other techniques have been applied, such as solid-phase microextraction (SPME) (Regueiro et al. 2009a), stir bar sorptive extraction (SBSE) (Casas Ferreira et al. 2010), and ultrasound-assisted emulsification microextraction (USAEME) (Regueiro et al. 2009b). The USAEME technique is variant liquid-liquid microextraction (LLME) and was first used by Regueiro 7 years ago (Regueiro et al. 2008). USAEME techniques are now widely employed due to a great number of advantages that they offer, such as low consumption of organic solvents, simplicity of experiment, high extraction efficiency, and low costs. The final stage of the determination of EDCs in environmental samples requires extremely sensitive and selective techniques. Currently, for this purpose, chromatographic methods are primarily used, i.e., gas chromatography (GC), high-performance liquid chromatography (HPLC), and ultrahigh-performance liquid chromatography (UHPLC). The detector typically employed in conjunction with chromatographic techniques is mass spectrometer (MS). Another detector applied and used in liquid chromatographic assays is ultraviolet detector (UV).

The aim of this work was to develop a quick and selective analytical method to carry out the determination of seven compounds from the group of PCPs (i.e., MP, EP, PP, BP, BP, DEET, and 4-MBC) and two hormones (i.e., E1 and E2) 
at low concentrations. USAEME has been used for the isolation whereas GC-MS in the selected ion monitoring (SIM) mode has been applied for the separation and determination of analytes. The effect of various extraction and derivatization parameters, i.e., the type and volume of organic solvent, extraction time, derivatization reagent volume, and kind and amount of buffering salt was investigated. The developed USAEME/GC-MS method was employed to determine target compounds in landfill leachate and groundwater samples from MSW landfill sites in Poland.

\section{Materials and methods}

\section{Reagents and solvents}

MP, EP, PP, BP, BPh, 4-MBC, DEET, E1, E2, octanol, decane, and urea were obtained from Sigma-Aldrich (Germany). Carbon tetrachloride was purchased from Merck (Germany). Chloroform, toluene, cyclohexane, sodium hydrogen phosphate $(\mathrm{V})$, magnesium sulfate (VI) anhydrous, sodium bicarbonate, anhydrous potassium carbonate, sodium nitrate $(\mathrm{V})$, and methanol were obtained from POCH (Poland). Acetic anhydride, ammonium bicarbonate (IV), magnesium chloride, potassium hydrogen phosphate $(\mathrm{V})$, potassium carbonate, and calcium chloride anhydrous were obtained from Chempur (Poland). Stock solutions of each analyte (at $1 \mathrm{mg} \mathrm{mL}^{-1}$ each) were prepared separately in methanol and stored at $-18{ }^{\circ} \mathrm{C}$ not longer than 1 month. Working solutions were prepared by diluting the stock standard solution in methanol and stored at $-18{ }^{\circ} \mathrm{C}$ not longer than 2 weeks. Deionized water was from purification system (Milli-Q RG, Millipore, USA) and was stored in glass bottle.

\section{Synthetic landfill leachate}

The synthetic landfill leachate was prepared in order to eliminate effects of the target compounds present in the real landfill leachate on the sensitivity of the method. The recipe was adapted from the research conducted by Champagne and Li (2009). The synthetic landfill leachate was prepared by dissolving the corresponding analytical grades of chemicals in distilled water as shown in Table 1.

\section{Real samples}

The landfill leachate was obtained from the three MSW landfill sites, and groundwater samples were collected from the two MSW landfill sites, all located in northeastern Poland. The samples were obtained from landfills for non-hazardous and inert waste, with different
Table 1 Synthetic landfill leachate composition

characteristics (different in size, kind of insulation, the method of collecting leachate, and age). Table 2 shows characteristics of studied MSW landfills. In MSW landfill site $\mathrm{A}$, the leachate is stored in opened lagoons, while in landfills B and C, leachate is stored in underground wells. The examined landfills discharged leachate to a wastewater treatment plant by tanker trucks. Additionally, in landfill $\mathrm{B}$, part of the leachates is recycled by spraying on the landfill cap. The groundwater samples were collected from piezometers located under the landfill sites. Samples of landfill leachate and groundwater samples were collected between April 2012 and May 2013. Samples were introduced into glass bottles and transported to the laboratory. All bottles and equipment used to collect leachate and groundwater samples were cleaned using an anionic detergent and were thoroughly rinsed with tap water followed by deionized water. After that, sampling bottles and equipment were rinsed with pesticide-free methanol and allowed to air dry. Upon arrival, the samples were filtered through a membrane filter with $0.45 \mu \mathrm{m}$ pore size and acidified with concentrated hydrochloric acid to $\mathrm{pH}=2$. Later, the real samples were stored at $-18{ }^{\circ} \mathrm{C}$.

\section{The procedure of ultrasound-assisted emulsification microextraction with in situ derivatization}

For the simultaneous USAEME and derivatization, aliquots of $5 \mathrm{~mL}$ water samples were placed in $10-\mathrm{mL}$ glass centrifuge tubes containing previously weighted $0.1 \mathrm{~g}$ of sodium hydrogen phosphate. The extraction solvent (chloroform, $70 \mu \mathrm{L}$ ) and the derivatization reagent (acetic anhydride, $50 \mu \mathrm{L}$ ) were added to the water sample and mixed. Immediately after, the tube was immersed in an ultrasonic Sonic-3, Polsonic (Poland) water bath in such a way that the levels of both liquids (i.e., the bath and the 
Table 2 Characteristics of study MSW landfills (Inspection of Environmental Protection and Inspectorate of Environmental Protection in Bialystok 2013)

\begin{tabular}{|c|c|c|c|c|c|c|}
\hline & Status & Capacity $\left(\mathrm{m}^{3}\right)$ & Kind of insulation & $\begin{array}{l}\text { Number of } \\
\text { piezometers }\end{array}$ & $\begin{array}{l}\text { Class }^{\mathrm{a}} \text { of groundwater } \\
\text { in } 2011\end{array}$ & $\begin{array}{l}\text { Class }^{\mathrm{a}} \text { of groundwater } \\
\text { in } 2012\end{array}$ \\
\hline MSW landfill A & Open & 242.311 & Mixed insulation (artificial/natural) & 4 & $\mathrm{~V}, \mathrm{~V}, \mathrm{~V}, \mathrm{~V}$ & $\mathrm{~V}, \mathrm{~V}, \mathrm{~V}, \mathrm{I}$ \\
\hline MSW landfill B & Open & 480.000 & PVC foil & 4 & II, II & II, I, II, II \\
\hline MSW landfill C & For the closure & 45.092 & n.d. & 4 & IV, V, V, IV & $\mathrm{V}, \mathrm{V}, \mathrm{V}, \mathrm{V}$ \\
\hline
\end{tabular}

${ }^{a}$ Based on the Regulation of the Minister of Environment of 23 July 2008, on the criteria and methods of evaluation of groundwater samples (Dz.U. Nr 143 poz. 896)

n.d. no data

sample) were equal. Extractions were performed at $42 \mathrm{kHz}$ of ultrasound frequency and $230 \mathrm{~W}$ of power for the duration of $5 \mathrm{~min}$ at a room temperature. Emulsions were disrupted by centrifugation at $4000 \mathrm{rpm}$ for $5 \mathrm{~min}$ in an MPW-250 Med. Instruments (Poland) laboratory centrifuge. In effect, the organic phase settled at the bottom of the conical tube. After centrifugation, chloroform was removed using a $100 \mu \mathrm{L}$ Hamilton syringe (USA) and transferred into a $150 \mu \mathrm{L}$ microvial with integrated insert.

To ensure the quality of results, the USAEME procedure was done in triplicate for all real samples as well as spiked samples used for method validation. Quality control samples used for method validation (synthetic landfill leachate and real groundwater samples) were examined for the presence of target compounds. Field blanks were prepared in field by processing deionized water through the sampling equipment in the same manner that real samples were collected. Three laboratory blanks and three field blanks were analyzed, and no one of nine target chemicals was detected.

\section{Gas chromatography-mass chromatography analysis}

Analysis was performed with a HP 6890 gas chromatograph with a mass spectrometric detector MSD5973 and HP 7673 autosampler (Agilent Technologies, USA). This device was equipped with ZB-5MSi (5\% phenylmethylsiloxane) size $30 \mathrm{~m}$ length $\times 0.25 \mathrm{~mm}$, i.e., coated with $0.25-\mu \mathrm{m}$ film thickness and split/splitless injector. The injector worked in splitless mode. Helium of purity $99.999 \%$ was used as carrier gas at flow rate $1 \mathrm{~mL} \mathrm{~min}{ }^{-1}$. The injector temperature was $250{ }^{\circ} \mathrm{C}$. The oven temperature was programmed from $150{ }^{\circ} \mathrm{C}$, increased at $5{ }^{\circ} \mathrm{C} \mathrm{min}{ }^{-1}$ to $185{ }^{\circ} \mathrm{C}$ and $20{ }^{\circ} \mathrm{C} \mathrm{min}{ }^{-1}$ to $270{ }^{\circ} \mathrm{C}$. The total run time was $17.25 \mathrm{~min}$. The $\mathrm{MS}$ detector worked in SIM mode. The electron impact source temperature was $230{ }^{\circ} \mathrm{C}$ with electron energy of $70 \mathrm{eV}$. The quadrupole temperature was $150{ }^{\circ} \mathrm{C}$, and the $\mathrm{GC}$ interface temperature was $280{ }^{\circ} \mathrm{C}$. The retention times and molecular weights of target compounds are shown in Table 3 together with the quantification and identification ions.

\section{Results and discussion}

\section{Optimization of extraction and derivatization procedure}

All tests during the optimization process had been carried out using distilled water containing $100 \mu \mathrm{g} \mathrm{L} \mathrm{L}^{-1}$ of each target compounds.

\section{Organic solvent selection}

Physicochemical properties of organic solvent, such as solubility in water, viscosity, and extraction capacity, have crucial impact on the efficiency of extraction process of target compounds. In the USAEME technique, the choice of solvent is also dictated by the possibility of forming emulsion during the extraction procedure. For application of the above conditions, chloroform, carbon tetrachloride, toluene, cyclohexane, $n$ decane, and 1-octanol were examined in the preliminary experiments. In their course, $70 \mu \mathrm{L}$ of solvent was added to $5 \mathrm{~mL}$ aliquots of the target compound solution, and the samples were placed in an ultrasonic bath for $5 \mathrm{~min}$. Emulsification was observed in all of the cases. After centrifugation, the extraction solvents with density higher than water (carbon tetrachloride and chloroform) were removed with syringe from the conical bottom of the test tube. Toluene, cyclohexane, $n$-decane, and 1-octanol, which have lower density than water, were collected from the bottom of the tube after removal of water. The results of organic solvent selection are shown in Fig. 1. In cases of MP, EP, PP, BP, DEET, BPh, 4-MBC, and E2, the largest peak areas were obtained using chloroform, whereas in case of E1, the largest peak areas were obtained using cyclohexane as the extraction solvent. That is why chloroform was eventually selected as the optimum extraction solvent for further experiment.

\section{Volume of extraction solvent}

The volume of extraction solvent is a crucial parameter that has an important effect on the extraction efficiency: The lower the volume of organic phase, the greater the concentration of 
Table 3 The retention times $\left(t_{\mathrm{R}}\right)$, quantification and identification ions $(\mathrm{m} / \mathrm{z})$, and molecular weights (MWs) of analytes not undergoing acetylation and acetylated derivatives of analytes

\begin{tabular}{llll} 
Analyte & Retention time $\left(t_{\mathrm{R}}\right)[\mathrm{min}]$ & Quantification and identification ions $(\mathrm{m} / \mathrm{z})$ & Molecular weight $(\mathrm{MW})$ \\
\hline \multicolumn{2}{l}{ Analytes not undergoing acetylation } & & \\
DEET & 5.85 & $91, \mathbf{1 1 9}, 190$ & 191 \\
BPh & 6.64 & $77, \mathbf{1 0 5}, 182$ & 182 \\
$4-\mathrm{MBC}$ & 10.76 & $128,171, \mathbf{2 5 4}$ & 254 \\
Acetylated derivatives of analytes & & \\
MP & 4.60 & $43, \mathbf{1 2 1}, 152$ & 194 \\
EP & 5.47 & $\mathbf{1 2 1}, 138,166$ & 208 \\
PP & 6.86 & $121, \mathbf{1 3 8}, 180$ & 222 \\
BP & 8.21 & $121, \mathbf{1 3 8}, 194$ & 236 \\
E1 & 16.16 & $185, \mathbf{2 7 0}, 272$ & 312 \\
E2 & 16.42 & $43,146, \mathbf{2 7 2}$ & 314 \\
\hline
\end{tabular}

Bold ions selected for monitoring the analyte, which effects in lowering the limit of quantification (LOQ). On the other hand, the amount of solvent recovered after the extraction process should be sufficient to carry out injection of the sample into the GC-MS device with the use of autosampler. To study the effect of extraction solvents, different volumes of chloroform $(70,100$, and $120 \mu \mathrm{L})$ were subjected to the USAEME procedure (Fig. 2). The analysis showed that reduction of solvent volume is accompanied by growth of peak areas of the analyzed compounds. The amount of solvent recovered after the extraction process, conducted with the use of $70 \mu \mathrm{L}$ of chloroform, ranged between 20 and $30 \mu \mathrm{L}$, and the used volume was the smallest which allowed introduction of the sample into chromatograph with autosampler. All in all, $70 \mu \mathrm{L}$ chloroform as extractant solvent was used in subsequent experiments.

\section{Effect of the extraction and derivatization time}

In USAEME, extraction time is defined as the time between injection of extraction solvent and the end of the sonication stage (Ma et al. 2009). The sonication time should provide the maximum dispersion which affects the extraction efficiency of the analyte. In the used procedure, at the same time, extraction and derivatization of analytes in the matrix were performed. An ultrasound-assisted process was adopted in a range of 5 15 min to evaluate its effect on extraction and derivatization (Fig. 3). Based on the obtained results, we found that there were no significant differences in signal intensities registered after individual extraction time, so the shortest extraction time 5 min was chosen as the most suitable for further studies. At this time, total derivatization of analytes occurred, which was confirmed by registered chromatograms and mass spectra.

\section{Effect of kind and amount of buffering salt}

In the derivatization technique with the use of acetic anhydride, an addition of buffer salt is necessary. Sodium hydrogen carbonate is the most frequently used for this purpose. However, in USAEME procedure, carbon dioxide bubbles are produced as a consequence of decomposition of carbonates
Fig. 1 The influence of organic solvent on extraction efficiency of target compounds $(n=3)$

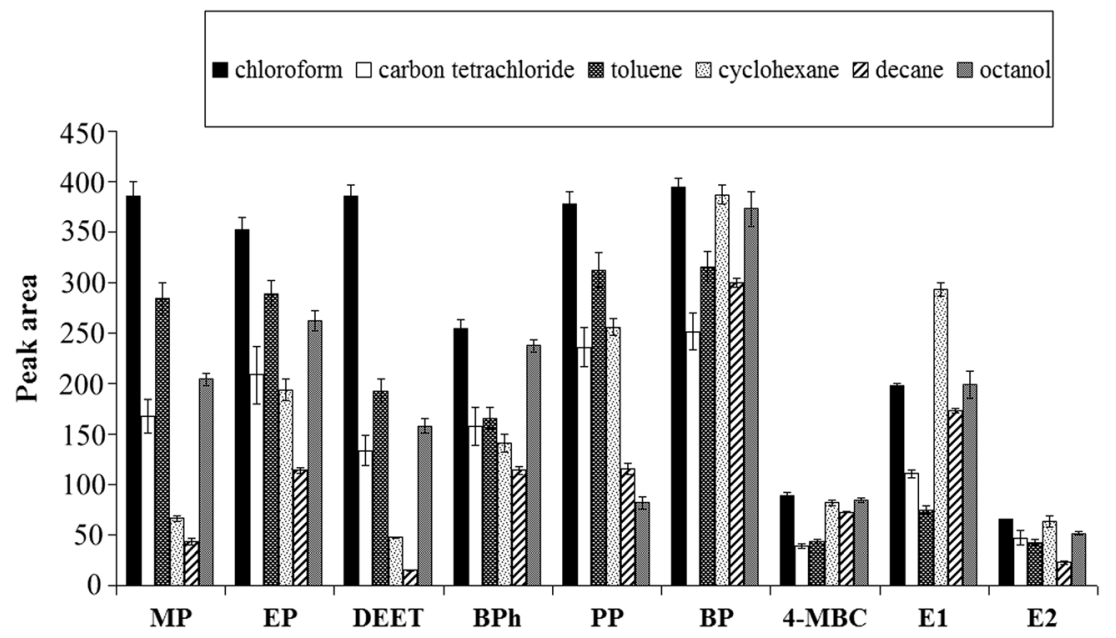


Fig. 2 The influence of volume of extraction solvent on extraction efficiency of target compounds $(n=3)$

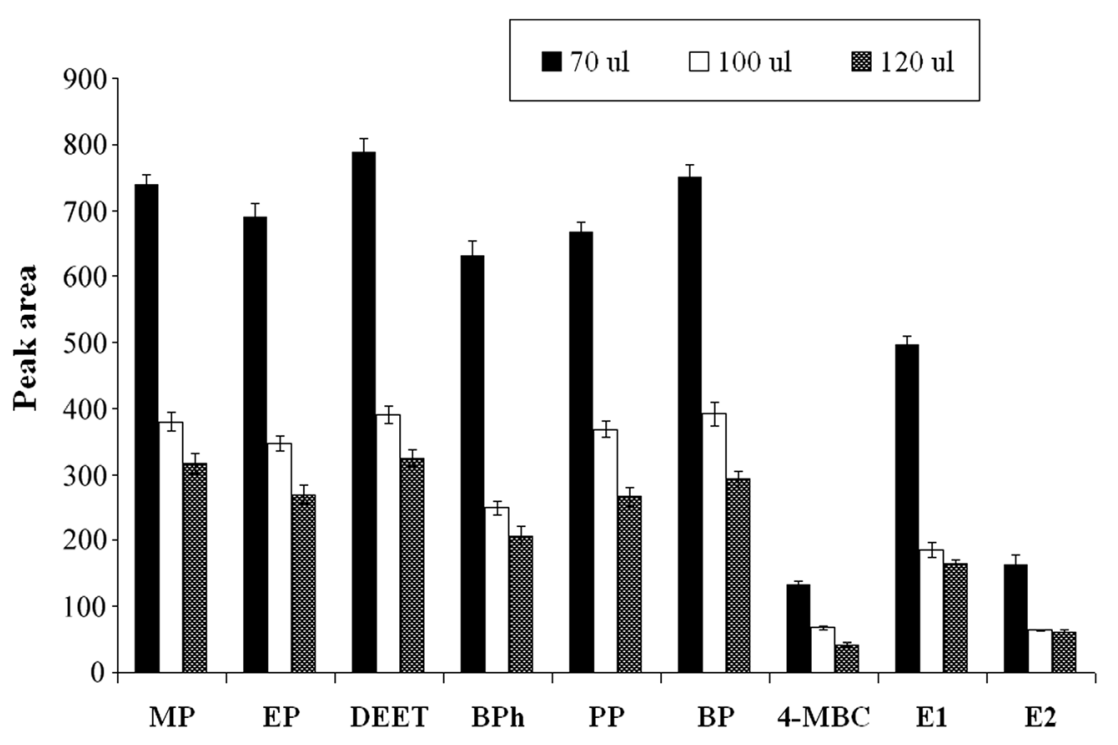

interfering with the collection of the organic phase, so in the present work, sodium hydrogen phosphate was used as the buffering salt. To study the effects of various amounts of added sodium hydrogen phosphate on the derivatization process, experiments were performed with different quantities of this salt $(0.05-0.2 \mathrm{~g})$ per $5 \mathrm{~mL}$ of wastewater sample. Figure 4 illustrates the influence of added quantity of sodium hydrogen phosphate on extraction efficiency of the target compounds. It can be noticed that the highest peak areas were obtained using $0.1 \mathrm{~g}$ of sodium hydrogen phosphate; therefore, $0.1 \mathrm{~g}$ was used in subsequent experiments.

\section{Effect of derivatization reagent volume}

The influence of the volume of acetic anhydride on the relative peak area was studied in the range of 20-300 $\mu \mathrm{L}$ (Fig. 5). The results indicated that the volume of acetic anhydride equal to $50 \mu \mathrm{L}$ should be chosen as optimal.

\section{Method validation}

To evaluate the developed USAEME-GC/MS method, the linearity, LOQ, and limit of detection (LOD), repeatability and recovery were investigated under the optimum conditions. The validation method was conducted by using deionized water as the sample matrix (Table 4) and also groundwater and synthetic landfill leachate as the sample matrix (Table 5). The calibration curves were built by spiking the synthetic landfill leachate and groundwater samples with 5 to 11 levels of concentration (depending on the analyzed compound and the kind of matrix used) and performing the extraction. The calibration curves were built on two levels of concentration for MP, EP, $\mathrm{PP}, \mathrm{BP}, \mathrm{BPh}$, and DEET and on one level of concentration for 4-MBC, E1, and E2. Calibration curves were linear within the studied concentration range, with coefficients of correlation higher than 0.981 for all the target compounds. The LOQ, determined as the analyte concentration corresponding to a
Fig. 3 The influence of extraction times on extraction efficiency of target compounds $(n=3)$

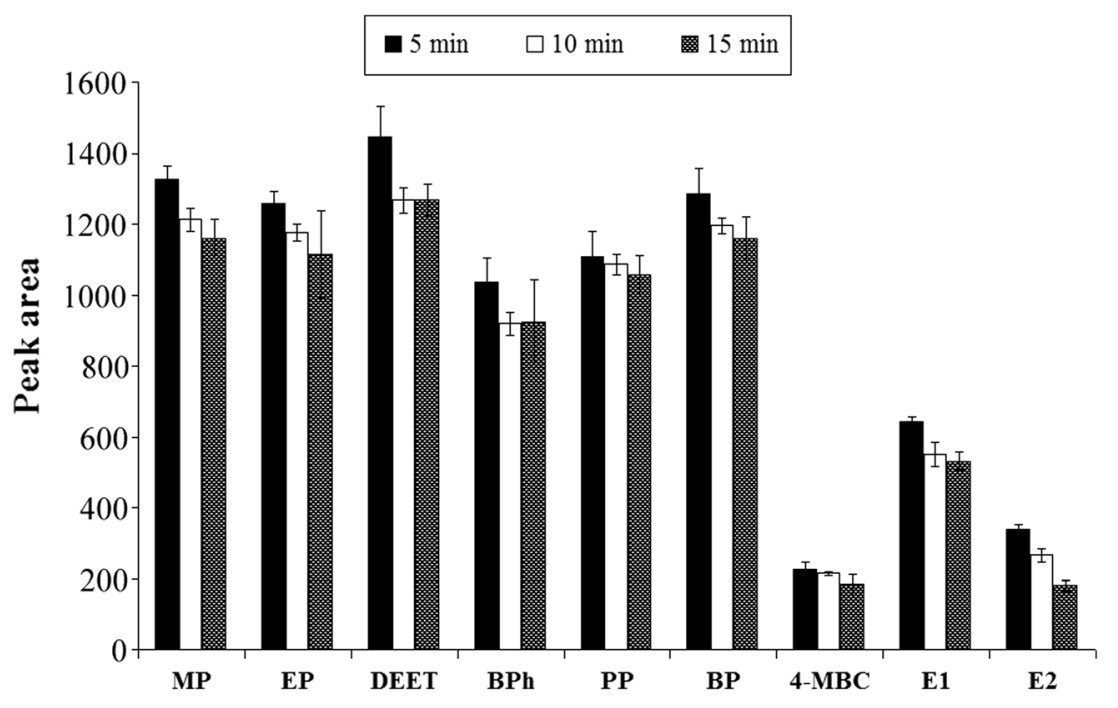


Fig. 4 The influence of kind and amount of buffering salt on extraction efficiency of target compounds $(n=3)$

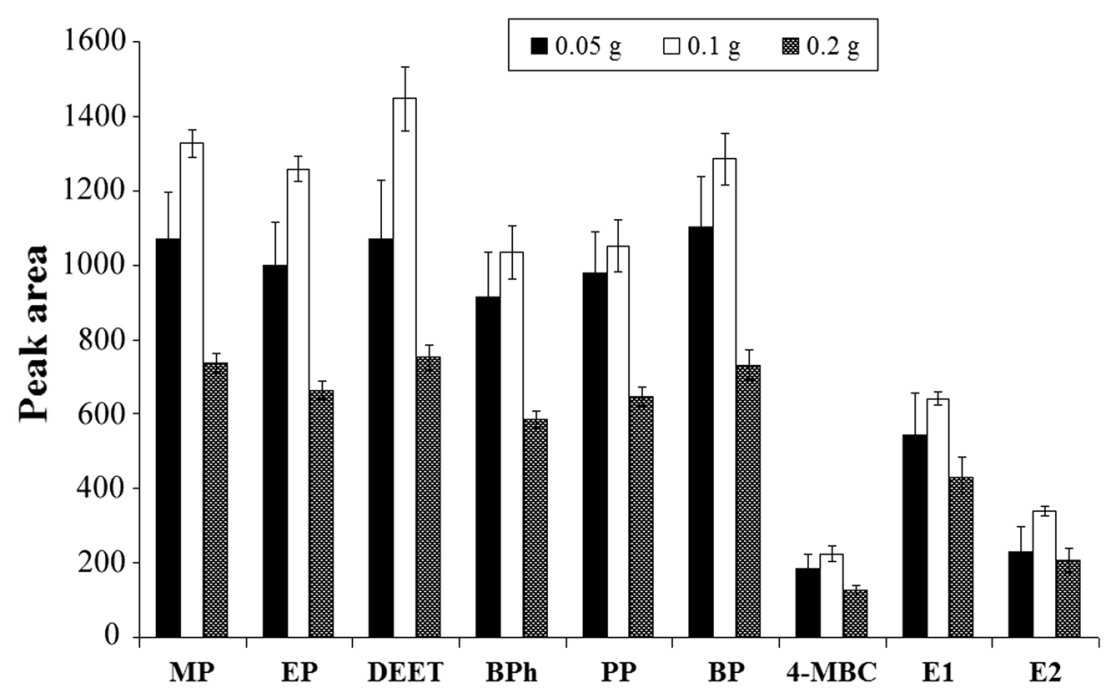

signal/noise ratio of 10 , were between 0.002 and $0.049 \mu \mathrm{g} \mathrm{L}-1$ by using groundwater as sample matrix and were between 0.001 and $0.278 \mu \mathrm{g} \mathrm{L}^{-1}$ by using synthetic landfill leachate as sample matrix. The LOD, defined as the concentration that corresponds to three times standard deviation of blanks, were between 0.001 and $0.015 \mu \mathrm{g} \mathrm{L}^{-1}$ by using groundwater as sample matrix and were between 0.003 and $0.083 \mu \mathrm{g} \mathrm{L}^{-1}$ using synthetic landfill leachate as sample matrix. Relative standard deviation (RSD) and recoveries were tested for two concentration levels $\left(0.09\right.$ and $8 \mu \mathrm{g} \mathrm{L}^{-1}$ in cases of groundwater samples and 0.8 and $7 \mu \mathrm{g} \mathrm{L}^{-1}$ in cases of synthetic landfill leachate samples). These values are presented in Table 5. RSD were below $21 \%$ for the lower concentration level, and RSD were below $16 \%$ for the higher concentration level. Recoveries were evaluated by spiking matrix before and after extraction; then, the obtained signals were compared. In the case when groundwater was used as the sample matrix, recoveries were between 85 and $136 \%$. When using landfill leachate as the sample matrix, the recoveries were between 83 and $136 \%$.

\section{Environmental sample analysis}

The developed USAEME/GC-MS method was applied for determination of MP, EP, PP, BP, BPh, 4-MBC, DEET, E1, and E2 in landfill leachate obtained from three MSW landfills and groundwater samples from two MSW landfill sites in northeast Poland. The chromatograms of landfill leachate (a) and groundwater samples (b) from MSW landfill B are shown in Fig. 6. The occurrence of target compounds and levels of contamination in the analyzed water samples are summarized in Table 6. The concentrations of the target compounds in landfill leachate were determined from calibration curves registered by analysis of spiked synthetic landfill leachate samples and the concentrations of the target compounds in groundwater. They were calculated on the basis of the calibration curve registered by the use of groundwater samples.

The PCP compounds were found in analyzed landfill leachate samples with $100 \%$ frequency. The concentrations were between 0.66 and $17.67 \mu \mathrm{g} \mathrm{L}^{-1}$ (median between 1.55 and $3.77 \mu \mathrm{g} \mathrm{L}^{-1}$ ), except DEET which was detected in
Fig. 5 The influence of derivatization reagent volume on extraction efficiency of target compounds $(n=3)$

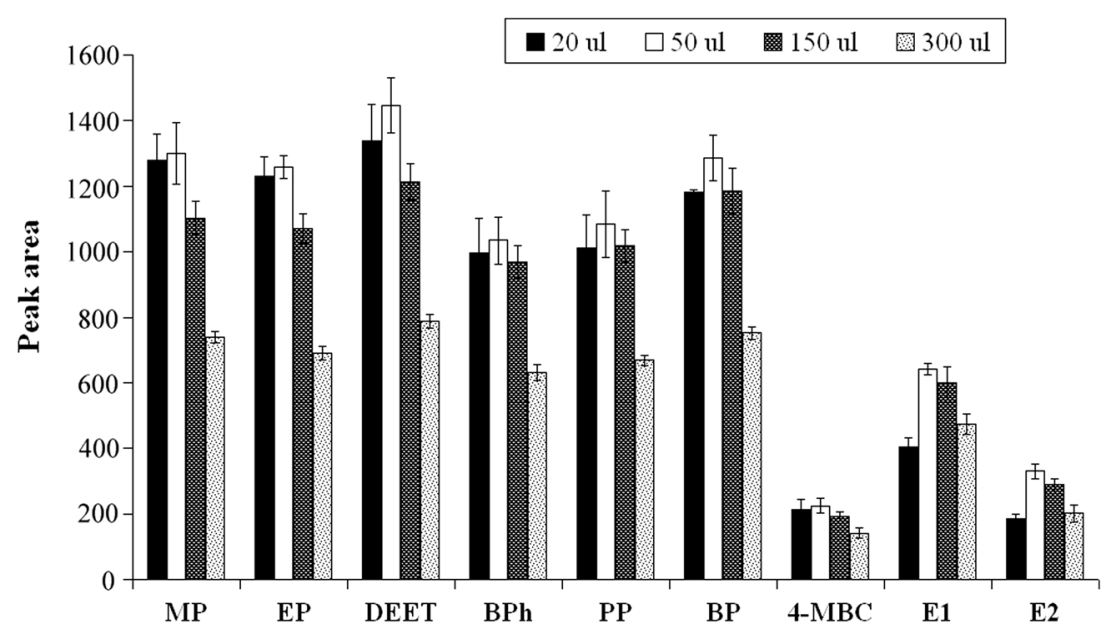


Table 4 Analytical characteristics of the USAEME/GC-MS method

\begin{tabular}{|c|c|c|c|c|c|c|c|c|c|c|}
\hline \multirow[t]{2}{*}{ Analyte } & \multicolumn{4}{|c|}{ Linearity $\left(\mu \mathrm{g} \mathrm{L}^{-1}\right)$} & \multirow[t]{2}{*}{$\operatorname{LOD}\left(\mu \mathrm{g} \mathrm{L}^{-1}\right)$} & \multirow[t]{2}{*}{$\operatorname{LOQ}\left(\mu \mathrm{g} \mathrm{L}^{-1}\right)$} & \multicolumn{2}{|c|}{$\operatorname{RSD}(\%, n=3)$} & \multicolumn{2}{|c|}{ Recovery $(\%, n=3)$} \\
\hline & Range I & $R^{2}$ & Range II & $R^{2}$ & & & $0.02 \mu \mathrm{g} \mathrm{L}^{-1}$ & $7 \mu \mathrm{g} \mathrm{L}^{-1}$ & $0.02 \mu \mathrm{g} \mathrm{L}^{-1}$ & $7 \mu \mathrm{g} \mathrm{L}^{-1}$ \\
\hline MP & $0.005-0.05$ & 0.9896 & $0.05-10$ & 0.9975 & 0.0006 & 0.0020 & 21.5 & 11.4 & 115.5 & 100.8 \\
\hline EP & $0.005-0.05$ & 0.9811 & $0.05-10$ & 0.9967 & 0.0011 & 0.0038 & 20.9 & 8.9 & 78.7 & 98.4 \\
\hline PP & $0.005-0.05$ & 0.9749 & $0.05-10$ & 0.9984 & 0.0004 & 0.0013 & 24.4 & 12.0 & 89.0 & 102.1 \\
\hline $\mathrm{BP}$ & $0.001-0.05$ & 0.9963 & $0.05-10$ & 0.9971 & 0.0001 & 0.0004 & 23.0 & 11.2 & 116.2 & 104.0 \\
\hline $\mathrm{BPh}$ & $0.001-0.05$ & 0.9938 & $0.05-10$ & 0.9972 & 0.0003 & 0.0008 & 24.2 & 11.6 & 115.1 & 106.1 \\
\hline 4-MBC & $0.005-0.05$ & 0.9782 & $0.05-10$ & 0.9931 & 0.0015 & 0.0048 & 17.4 & 7.8 & 72.5 & 100.4 \\
\hline E1 & $0.005-0.05$ & 0.9926 & $0.05-10$ & 0.9975 & 0.0014 & 0.0048 & 23.6 & 9.7 & 103.0 & 99.7 \\
\hline E2 & $0.005-0.05$ & 0.9998 & $0.05-10$ & 0.9931 & 0.0014 & 0.0046 & 23.1 & 10.2 & 124.2 & 103.8 \\
\hline DEET & $0.005-0.05$ & 0.9861 & $0.05-10$ & 0.9913 & 0.0006 & 0.0019 & 23.6 & 13.2 & 127.4 & 103.0 \\
\hline
\end{tabular}

$L O D$ limit of detection, $L O Q$ limit of quantification

leachates from all the examined landfills in concentrations reaching hundreds of micrograms per liter (median 32.83). The average values of the concentration of target compounds were found on the level of several micrograms per liter, except DEET with the average value $71.16 \mu \mathrm{g} \mathrm{L}^{-1}$. Hormones were detected in landfill leachate samples in concentration reaching hundreds of nanograms per liter (median
$0.122 \mu \mathrm{g} \mathrm{L}^{-1}$ for E1 and $0.238 \mu \mathrm{g} \mathrm{L}^{-1}$ for E2). E1 was detected and quantified in one sample from each landfill (frequency $33 \%$ ), while E2 was detected in two leachate samples from landfill A (frequency $22 \%$ ). The concentrations of determined PCP compounds in groundwater samples varied from values below LOD to few micrograms per liter except DEET and 4-MBC in which concentrations were larger than

Table 5 Analytical characteristics of the USAEME/GC-MS method obtained with the use of groundwater and synthetic landfill leachates as the sample matrix

\begin{tabular}{|c|c|c|c|c|c|c|c|c|c|c|}
\hline \multirow[t]{2}{*}{ Analyte } & \multicolumn{4}{|c|}{ Linearity $\left(\mu \mathrm{g} \mathrm{L}^{-1}\right)$} & \multirow[t]{2}{*}{$\operatorname{LOD}\left(\mu \mathrm{g} \mathrm{L}^{-1}\right)$} & \multirow[t]{2}{*}{$\operatorname{LOQ}\left(\mu \mathrm{g} \mathrm{L}^{-1}\right)$} & \multicolumn{2}{|l|}{$\operatorname{RSD}(\%, n=3)$} & \multicolumn{2}{|c|}{ Recovery $(\%, n=3)$} \\
\hline & Range I & $R^{2}$ & Range II & $R^{2}$ & & & & & & \\
\hline \multicolumn{7}{|c|}{ Groundwater } & $0.09 \mu \mathrm{g} \mathrm{L}^{-1}$ & $8 \mu \mathrm{g} \mathrm{L}^{-1}$ & $0.09 \mu \mathrm{g} \mathrm{L}^{-1}$ & $8 \mu \mathrm{g} \mathrm{L}^{-1}$ \\
\hline MP & $0.005-0.05$ & 0.9910 & $0.05-10$ & 0.9915 & 0.001 & 0.002 & 15 & 11 & 109 & 98 \\
\hline EP & $0.005-0.05$ & 0.9921 & $0.05-10$ & 0.9922 & 0.001 & 0.004 & 21 & 9 & 119 & 91 \\
\hline PP & $0.005-0.05$ & 0.9931 & $0.05-10$ & 0.9902 & 0.001 & 0.003 & 18 & 13 & 96 & 105 \\
\hline BP & $0.005-0.05$ & 0.9996 & $0.05-10$ & 0.9950 & 0.001 & 0.003 & 20 & 13 & 93 & 108 \\
\hline $\mathrm{BPh}$ & $0.005-0.05$ & 0.9875 & $0.05-10$ & 0.9946 & 0.001 & 0.002 & 18 & 11 & 113 & 107 \\
\hline 4-MBC & $0.05-10$ & 0.9806 & - & - & 0.014 & 0.047 & 14 & 10 & 85 & 103 \\
\hline E1 & $0.05-10$ & 0.9976 & - & - & 0.005 & 0.017 & 16 & 12 & 136 & 103 \\
\hline E2 & $0.05-10$ & 0.9933 & - & - & 0.015 & 0.049 & 16 & 12 & 124 & 90 \\
\hline DEET & $0.005-0.05$ & 0.9925 & $0.05-10$ & 0.9905 & 0.001 & 0.003 & 20 & 14 & 114 & 108 \\
\hline \multicolumn{7}{|c|}{ Synthetic landfill leachate } & $0.8 \mu \mathrm{g} \mathrm{L}^{-1}$ & $7 \mu \mathrm{g} \mathrm{L}^{-1}$ & $0.8 \mu \mathrm{g} \mathrm{L}^{-1}$ & $7 \mu \mathrm{g} \mathrm{L}^{-1}$ \\
\hline MP & $0.05-2$ & 0.9924 & $2-12$ & 0.9967 & 0.010 & 0.033 & 13 & 12 & 96 & 104 \\
\hline EP & $0.05-2$ & 0.9976 & $2-12$ & 0.9959 & 0.016 & 0.053 & 17 & 11 & 83 & 90 \\
\hline PP & $0.03-2$ & 0.9933 & $2-12$ & 0.9973 & 0.009 & 0.030 & 18 & 15 & 110 & 96 \\
\hline BP & $0.05-2$ & 0.9963 & $2-12$ & 0.9969 & 0.014 & 0.046 & 16 & 1 & 115 & 110 \\
\hline $\mathrm{BPh}$ & $0.03-2$ & 0.9991 & $2-12$ & 0.9988 & 0.001 & 0.013 & 13 & 12 & 111 & 109 \\
\hline 4-MBC & $0.5-12$ & 0.9941 & - & - & 0.056 & 0.188 & 14 & 13 & 88 & 109 \\
\hline E1 & $0.5-12$ & 0.9944 & - & - & 0.036 & 0.121 & 15 & 13 & 127 & 91 \\
\hline E2 & $0.5-12$ & 0.9970 & - & - & 0.083 & 0.278 & 16 & 15 & 136 & 83 \\
\hline DEET & $0.01-1$ & 0.9899 & $1-12$ & 0.9953 & 0.003 & 0.009 & 20 & 16 & 118 & 109 \\
\hline
\end{tabular}

$L O D$ limit of detection, $L O Q$ limit of quantification 


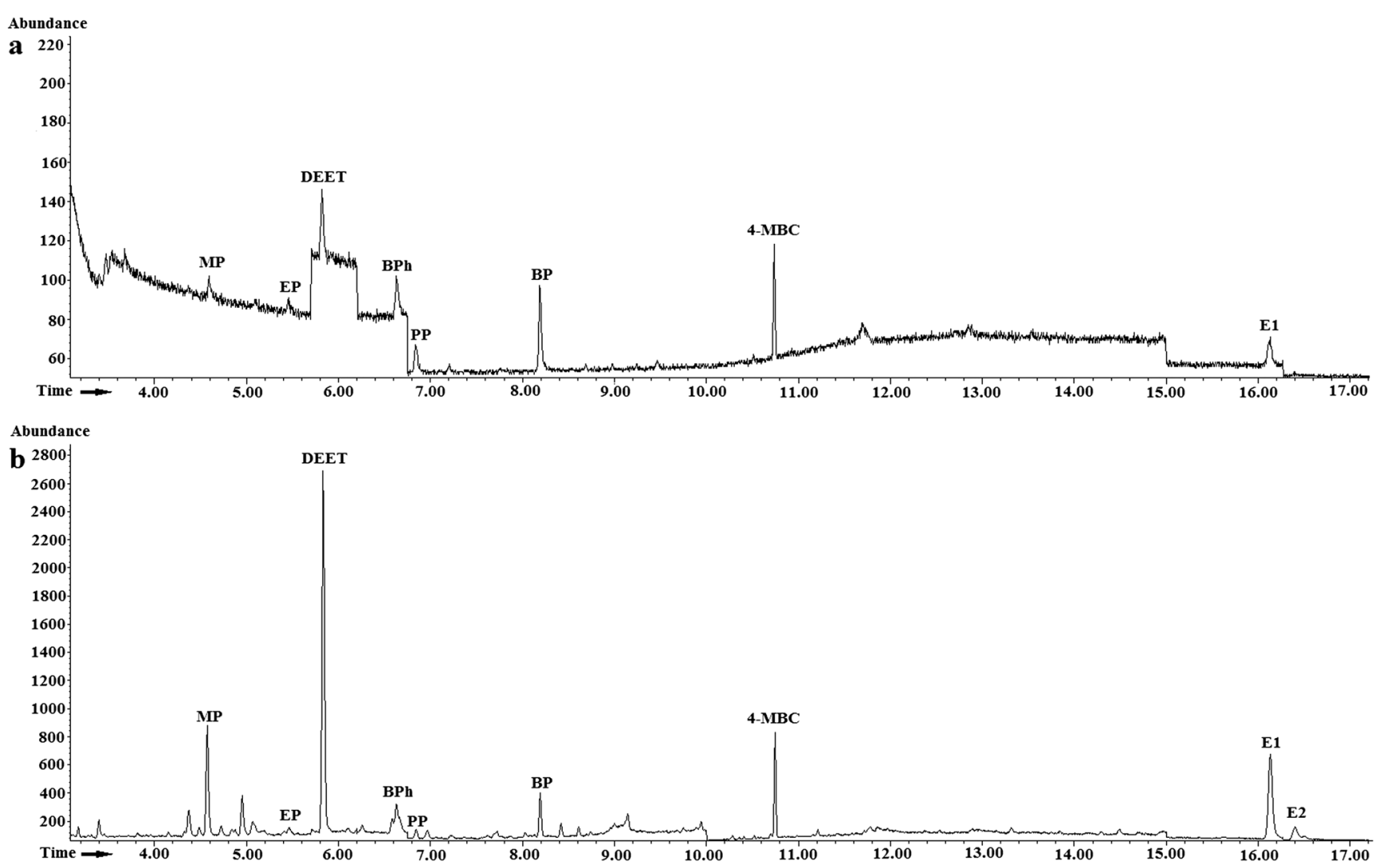

Fig. 6 The chromatograms registered during analysis of groundwater (a) and landfill leachate (b) samples from MSW landfill B

$1 \mu \mathrm{g} \mathrm{L}^{-1}$ in the same samples (median between 0.01 and $0.262 \mu \mathrm{g} \mathrm{L}^{-1}$ ). PP, BPh, and DEET were detected in $100 \%$ of groundwater samples, while MP and 4-MBC were quantified in $63 \%$; EP and BP were quantified in $25 \%$ of groundwater samples. Hormones were detected in groundwater samples in concentrations reaching several dozen of nanograms per liter. E1 was quantified in $19 \%$ of groundwater samples - two samples from landfill A and one sample from landfill B. E2 was detected in two groundwater samples from landfill A (frequency $12 \%$ ).

Table 6 Concentration of the target endocrine disrupting compounds in landfill leachates and groundwater samples from MSW landfill located in northeastern Poland

\begin{tabular}{|c|c|c|c|c|c|c|c|}
\hline \multirow[t]{3}{*}{ Analyte } & \multicolumn{7}{|c|}{ Range of concentration $\left(\mu \mathrm{g} \mathrm{L}^{-1} ; n=3\right)$} \\
\hline & \multicolumn{4}{|l|}{ Landfill leachate } & \multicolumn{3}{|l|}{ Groundwater } \\
\hline & $\begin{array}{l}\text { MSW landfill A } \\
(\mathrm{NS}=5)\end{array}$ & $\begin{array}{l}\text { MSW landfill B } \\
(\mathrm{NS}=2)\end{array}$ & $\begin{array}{l}\text { MSW landfill C } \\
(\mathrm{NS}=2)\end{array}$ & $\begin{array}{l}\text { Median in } \\
\text { leachate }\end{array}$ & $\begin{array}{l}\text { MSW landfill A } \\
(\mathrm{NS}=12)\end{array}$ & $\begin{array}{l}\text { MSW landfill B } \\
(\mathrm{NS}=4)\end{array}$ & $\begin{array}{l}\text { Median in } \\
\text { groundwater }\end{array}$ \\
\hline MP & $1.15-3.86$ & $3.33-17.15$ & $1.07-1.59$ & 2.35 & $0.036-0.459$ & $<$ LOQ -0.305 & 0.060 \\
\hline EP & $2.24-9.38$ & $1.10-5.19$ & $0.66-1.19$ & 2.24 & $<\mathrm{LOD}-0.086$ & $<\mathrm{LOD}-0.064$ & 0.070 \\
\hline PP & $1.65-5.90$ & $0.69-1.77$ & $0.93-2.31$ & 1.91 & $0.004-0.012$ & $0.003-0.025$ & 0.010 \\
\hline $\mathrm{BP}$ & $1.22-6.67$ & $0.75-2.30$ & $0.80-2.38$ & 1.55 & $<$ LOD -0.019 & $<$ LOD -0.032 & 0.012 \\
\hline $\mathrm{BPh}$ & $0.72-3.63$ & $0.95-3.33$ & $1.13-3.86$ & 1.98 & $0.028-0.492$ & $0.038-0.068$ & 0.062 \\
\hline 4-MBC & $1.22-16.64$ & $2.81-6.18$ & $5.20-7.79$ & 3.77 & $<$ LOD -3.625 & $<$ LOD -2.383 & 0.262 \\
\hline E1 & $<$ LOD -0.17 & $<$ LOD- 0.12 & $<$ LOD- 0.12 & 0.12 & $<\mathrm{LOD}-0.026$ & $<$ LOD -0.043 & 0.026 \\
\hline E2 & $<$ LOD -0.28 & $<\mathrm{LOD}$ & $<\mathrm{LOD}$ & 0.24 & $<$ LOD -0.048 & $<\mathrm{LOD}$ & 0.039 \\
\hline DEET & $11.41-132.97$ & $28.27-202.42$ & $32.92-101.71$ & 32.83 & $0.019-16.901$ & $0.023-0.047$ & 0.053 \\
\hline
\end{tabular}

NS number of samples, $L O Q$ limit of quantification, $L O D$ limit of detection 


\section{Conclusion}

In the present study, an analytical methodology based on ultrasound-assisted emulsification microextraction followed by GC-MS determination has been proposed for determination of natural hormones, parabens, BPh, DEET, and 4-MBC. In situ derivatization with acetic anhydride conducted simultaneously with extraction was successful under the optimized conditions. The proposed USAEME technique with in situ derivatization step offers several advantages in terms of simplicity, low cost, minimal solvent consumption, and very short time of sample preparation. The proposed method was successfully applied for determination of the studied PCPs and hormones in landfill leachate and groundwater samples obtained from three municipal solid waste landfill sites in northeast Poland. All the studied compounds were found in the leachates from Polish MSW landfills; the concentrations were between hundredths of micrograms per liter and several hundreds of micrograms per liter. The concentrations of pollutants in groundwater samples varied from values below LOD to several of micrograms per liter.

Acknowledgments The project was financed by the National Science Centre, based on the decisions number DEC-2013/09/N/ST10/02544.

Open Access This article is distributed under the terms of the Creative Commons Attribution 4.0 International License (http:// creativecommons.org/licenses/by/4.0/), which permits unrestricted use, distribution, and reproduction in any medium, provided you give appropriate credit to the original author(s) and the source, provide a link to the Creative Commons license, and indicate if changes were made.

\section{References}

Alkassasbe JYM, Heng LY, Surif S (2009) Toxicity testing and the effect of landfill leachate in Malaysia on behavior of common carp (Cyprinus carpio L., 1758; Pisces, Cyprinidae). Am J Environ Sci 5:209-217

Asakura H, Matsuto T, Tanaka N (2004) Behavior of endocrinedisrupting chemicals in leachate from MSW landfill sites in Japan. Waste Manage 24:613-622

Calza P, Medana C, Raso E, Giancotti V, Minero C (2011) N,N-diethyl$\mathrm{m}$-toluamide transformation in river water. Sci Total Environ 409: 3894-3901

Casas Ferreira AM, Möder M, Fernández Laespada ME (2010) GC-MS determination of parabens, triclosan and methyl triclosan in water by in situ derivatisation and stir-bar sorptive extraction. Anal Bioanal Chem 399:945-953

Champagne P, Li C (2009) Use of Sphagnum peat moss and crushed mollusk shells in fixed-bed columns for the treatment of synthetic landfill leachate. J Mater Cycles Waste Manage 11:339-347

Costanzo SD, Watkinson AJ, Murby EJ, Kolpin DW, Sandstrom MW (2007) Is there a risk associated with the insect repellent DEET (N, $\mathrm{N}$-diethyl-m-toluamide) commonly found in aquatic environments? Sci Total Environ 384:214-220

Dos Santos FL, Campos B, de Araújo M, Goreti Rodrigues Vale M, Caramão EB (2004) Application of activated carbon in the characterization of nitrogen compounds and phthalates in a landfill leachate. Microchem J 78:61-64

European Commission (1976) European Directive 76/768/EEC and its successive amendments, basic act 31976L0768., http://europa.eu. int/eurlex/en/lif/reg/en_register_133016.html

Foo KY, Lee LK, Hameed BH (2013) Batch adsorption of semi-aerobic landfill leachate by granular activated carbon prepared by microwave heating. Chem Eng J 222:259-264

Gracia-Lor E, Martínez M, Sancho JV, Peñuela G, Hernández F (2012) Multi-class determination of personal care products and pharmaceuticals in environmental and wastewater samples by ultra-high performance liquid-chromatography-tandem mass spectrometry. Talanta 99:1011-1023

Harvey PW, Everett DJ (2004) Significance of the detection of esters of phydroxybenzoic acid(parabens) in human breast tumours. J Appl Toxicol 24:1-4

Inspection of Environmental Protection, Inspectorate of Environmental Protection in Bialystok (2013) State of the Environment Report Podlaskie Province in 2011-2012

Kalka J (2012) Landfill leachate toxicity removal in combined treatment with municipal wastewater. Sci World J 12:1-7

Kalmykova Y, Björklund K, Strömvall A-M, Blom L (2013) Partitioning of polycyclic aromatic hydrocarbons, alkylphenols, bisphenol A and phthalates in landfill leachates and stormwater. Water Res 47: $1317-1328$

Kotowska U, Kapelewska J, Sturgulewska J (2013) Determination of phenols and pharmaceuticals in municipal wastewaters from Polish treatment plants by ultrasound-assisted emulsificationmicroextraction followed by GC-MS. Environ Sci Pollut R 21: $660-673$

Kumar V, Nakada N, Yasojima M, Yamashita N, Johnson AC, Tanaka H (2009) Rapid determination of free and conjugated estrogen in different water matrices by liquid chromatography-tandem mass spectrometry. Chemosphere 77:1440-1446

Kurata Y, Ono Y, Ono Y (2008) Occurrence of phenols in leachates from municipal solid waste landfill sites in Japan. J Mater Cycles Waste Manage 10:144-152

Kwan CS, Takada H, Mizukawa K, Torii M, Koike T, Yamashita R, Rinawati Saha M, Santiago EC (2012) PBDEs in leachates from municipal solid waste dumping sites in tropical Asian countries: phase distribution and debromination. Environ Sci Pollut R 20: 4188-4204

Liu Y-S, Ying G-G, Shareef A, Kookana RS (2011) Simultaneous determination of benzotriazoles and ultraviolet filters in ground water, effluent and biosolid samples using gas chromatography-tandem mass spectrometry. J Chromatogr A 1218:328-5335

Liu Y-S, Ying G-G, Shareef A, Kookana RS (2012) Occurrence and removal of benzotriazoles and ultraviolet filters in a municipal wastewater treatment plant. Environ Pollut 165:225-232

Loos R, Tavazzi S, Paracchini B, Canuti E, Weissteiner C (2013) Analysis of polar organic contaminants in surface water of the northern Adriatic Sea by solid-phase extraction followed by ultrahighpressure liquid chromatography-QTRAP ${ }^{\circledR}$ MS using a hybrid triple-quadrupole linear ion trap instrument. Anal and Bioanal Chem 405:5875-5885

Ma JJ, Du X, Zhang JW, Li JC, Wang LZ (2009) Ultrasound-assisted emulsification-microextraction combined with flame atomic absorption spectrometry for determination of trace cadmium in water samples. Talanta 80:980-984

Nomngongo PN, Catherine Ngila J, Msagati TAM, Gumbi BP, Iwuoha EI (2012) Determination of selected persistent organic pollutants in wastewater from landfill leachates, using an amperometric biosensor. Phys Chem Earth, Parts A/B/C 50-52:252-261

Odusanya DO, Okonkwo JO, Botha B (2009) Polybrominated diphenyl ethers (PBDEs) in leachates from selected landfill sites in South Africa. Waste Manage 29:96-102 
Pietrogrande MC, Basaglia G (2007) GC-MS analytical methods for the determination of personal-care products in water matrices. TrAC Trend Anal Chem 26:1086-1094

Preiss A, Berger-Preiss E, Elend M, Gerling S, Kühn S, Schuchardt S (2012) A new analytical approach for the comprehensive characterization of polar xenobiotic organic compounds downgradient of old municipal solid waste (MSW) landfills. Anal Bioanal Chem 403: 2553-2561

Regueiro J, Llompart M, Garcia-Jares C, Garcia-Monteagudo JC, Cela R (2008) Ultrasound-assisted emulsification-microextraction of emergent contaminants and pesticides in environmental waters. $\mathrm{J}$ Chromatogr A 1190:27-38

Regueiro J, Becerril E, Garcia-Jares C, Llompart M (2009a) Trace analysis of parabens, triclosan and related chlorophenols in water by headspace solid-phase microextraction with in situ derivatization and gas chromatography-tandem mass spectrometry. J Chromatogr A 1216:4693-4702

Regueiro J, Llompart M, Psillakis E, Garcia-Monteagudo JC, GarciaJares C (2009b) Ultrasound-assisted emulsification-microextraction of phenolic preservatives in water. Talanta 79:1387-1397

Renou S, Givaudan JG, Poulain S, Dirassouyan F, Moulin P (2008) Landfill leachate treatment: review and opportunity. J Hazard Mater 150:468-493

Rosi-Marshall EJ, Royer TV (2012) Pharmaceutical compounds and ecosystem function: an emerging research challenge for aquatic ecologists. Ecosystems 15:867-880
Streets S (2008) Endocrine Disrupting Compounds: A Report to the Minnesota Legislature. Minnesota Pollution Control Agency. http://www.pca.state.mn.us/index.php/view-document.html?gid= 3943

Trenholm RA, Vanderford BJ, Drewes JE, Snyder SA (2008) Determination of household chemicals using gas chromatography and liquid chromatography with tandem mass spectrometry. J Chromatogr A 1190:253-262

Yamamoto T, Yasuhara A, Shiraishi H, Nakasugi O (2001) Bisphenol A in hazardous waste landfill leachates. Chemosphere 42:415-418

Zhang Y, Lee HK (2012) Determination of ultraviolet filters in water samples by vortex-assisted dispersive liquid-liquid microextraction followed by gas chromatography-mass spectrometry. J Chromatogr A 1249:25-31

Zhang Y, Lee HK (2013) Determination of ultraviolet filters in environmental water samples by temperature-controlled ionic liquid dispersive liquid-phase microextraction. J Chromatogr A 1271: 56-61

Zhang C, Eganhouse RP, Pontolillo J, Cozzarelli IM, Wang Y (2012) Determination of nonylphenol isomers in landfill leachate and municipal wastewater using steam distillation extraction coupled with comprehensive two-dimensional gas chromatography/time-of-flight mass spectrometry. J Chromatogr A 1230:110-116 